Document downloaded from:

http://hdl.handle.net/10251/49298

This paper must be cited as:

Benajes Calvo, JV.; Molina Alcaide, SA.; García Martínez, A.; Belarte Mañes, E.;

Vanvolsem, M. (2014). An investigation on RCCl combustion in a heavy duty diesel engine using in-cylinder blending of diesel and gasoline fuels. Applied Thermal Engineering. 63(1):66-76. doi:10.1016/j.applthermaleng.2013.10.052.

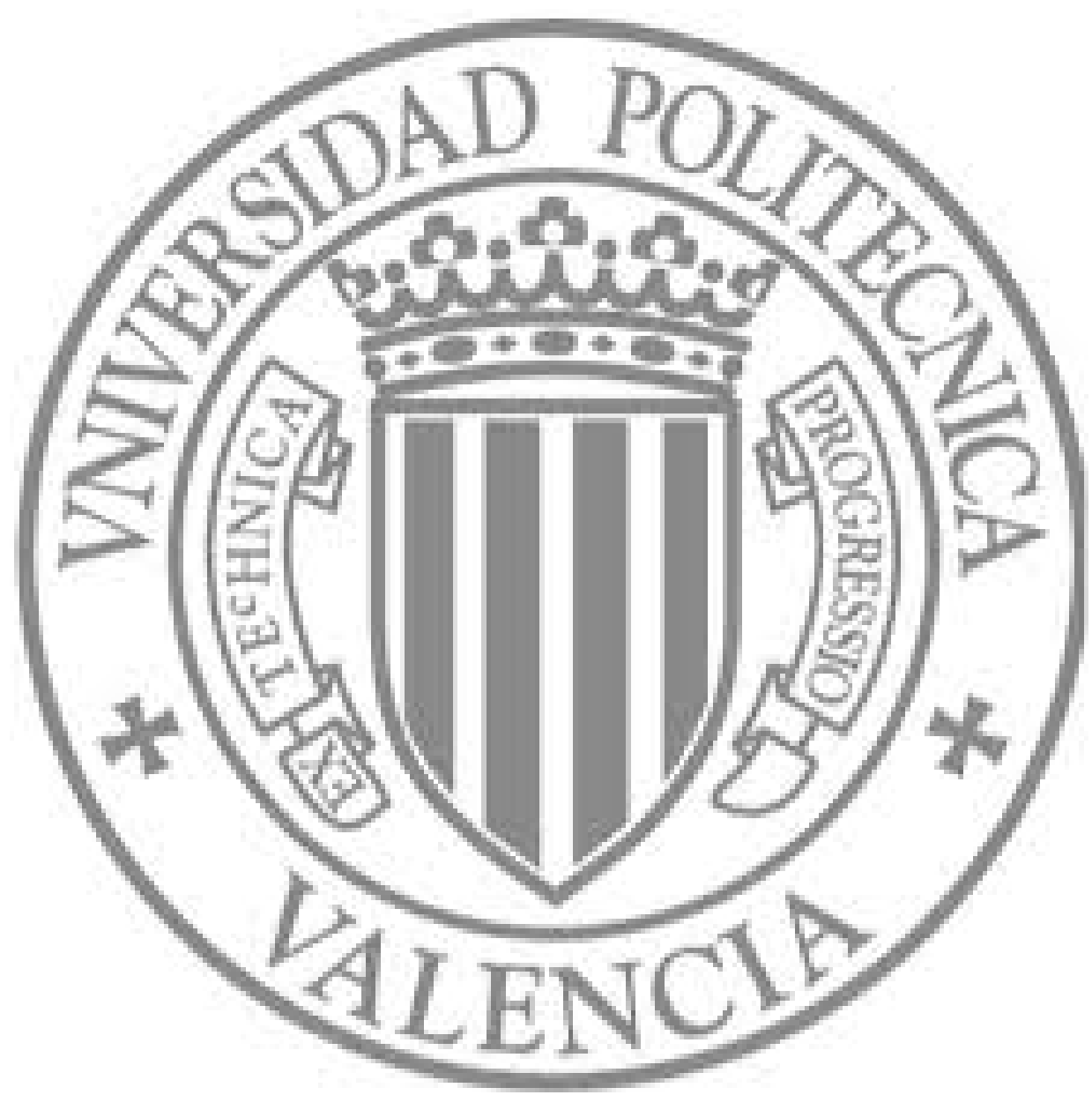

The final publication is available at

http://dx.doi.org/10.1016/j.applthermaleng.2013.10.052

Copyright Elsevier 


\title{
An Investigation on RCCI Combustion in a Heavy Duty Diesel Engine using In-Cylinder Blending of Diesel and Gasoline Fuels
}

\author{
Jesús Benajes ${ }^{1}$, Santiago Molina ${ }^{1}$, Antonio García ${ }^{1}$ and Eduardo Belarte ${ }^{1}$ \\ Michel Vanvolsem² \\ 1: CMT- Motores Térmicos - Universidad Politécnica de Valencia, Camino de Vera s/n 46022 Valencia - SPAIN \\ 2: Volvo Group Trucks Technology - 99 Route de Lyon, 69806 Saint Priest, FRANCE
}

\begin{abstract}
An experimental and numerical study has been carried out to understand mixing and auto-ignition processes in $\mathrm{RCCl}$ combustion conditions, using gasoline and diesel as low and high reactivity fuels, respectively.

Three parametrical studies have been developed using a heavy duty compression ignition engine equipped with a direct injector and a port fuel injector, to be able to vary the in-cylinder fuel blending ratio. Besides, a detailed analysis in terms of air/fuel mixing process has also been performed by means of a 1-D spray model.

It is found that combustion starts with the auto-ignition of the diesel injection and the air and gasoline entrained. Then, the temperature and pressure raise starts the flame propagation across the lean diesel and gasoline zones of the combustion chamber. As the Diesel/Gasoline fuel ratio is reduced, the ignition delay increases extending the mixing time and the first combustion stage gets lowered while the second one is enhanced. The advance of the diesel injection timing enlarges the mentioned effects over the combustion process. With respect to conventional neat diesel combustion, a slight reduction in terms of NOx and a very important reduction in terms of soot were achieved with the $\mathrm{RCCl}$ combustion.
\end{abstract}

Keywords: Reactivity Controlled Compression Ignition, Dual Fuel combustion emissions, in-cylinder fuel blending. 


\section{Introduction}

Nowadays automotive scientific community and companies focus part of their efforts on the investigation of new combustion modes [1] and on the optimization of the current technology with the aim of reducing fuel consumption and emissions in internal combustion engines (ICE) [2], more specifically in $\mathrm{Cl}$ (Compression Ignition) diesel engines [3]. Most of these new combustion concepts are achieved by using different strategies that produce a leaner mixture, using medium and high levels of EGR to provide low temperature combustions with the objective of decoupling the injection and combustion events. Consequently, high efficiency is achieved along with a decrease in the most relevant $\mathrm{Cl}$ diesel engine emissions, NOx and soot [4] [5]. These combustion concepts based on partially or fully premixed lean mixtures are commonly known as Homogeneous Charge Compression Ignition $(\mathrm{HCCl})$, Premixed Charge Compression Ignition (PCCl), etc. Despite their important emissions benefits [6], these combustion concepts present some practical issues that must be overcome before they could be implemented in $\mathrm{Cl}$ diesel engines. The most relevant limitations consist of achieving an appropriate combustion phasing, the cycle-to-cycle control of the combustion process, the noise and the operation at high load conditions.

With the aim of overcoming the mentioned drawbacks, different strategies have been proposed in the last few years [7]. Some of the most relevant ones are: the control of the intake air temperature, the modification of the compression ratio, the use of different injection strategies and the control of the intake oxygen concentration [8]. At the end, all these strategies try to compensate the high chemical reactivity of the diesel fuel, by modifying the gas properties. By contrast, recent studies tried to overcome the disadvantages previously described by modifying fuel properties, reducing fuel reactivity to slow down chemical reactions and delay auto-ignition [9].

On this regard, $\mathrm{RCCl}$ combustion concept, also named Dual Fuel $\mathrm{PCCl}$, has arisen as a combustion mode in which combustion is controlled mainly by fuel reactivity [10]. This combustion mode symbolizes an evolution from the Premixed Charge Compression Ignition (PCCl) concept, because fuel and air are mixed before combustion, but in this case fuel reactivity varies across the cylinder. Recently Hanson et al. confirmed how combustion phasing could be controlled by handling auto-ignition, varying fuel reactivity. Also stated how fuel reactivity stratification is needed to control the rate of heat released, initiated by the diesel fuel auto-ignition and propagated to the less reactive zones [11]. Moreover, other authors also confirm that the in-cylinder blending of different reactivity fuel provides the potential of simultaneous reduction of NOx and soot emissions for $\mathrm{Cl}$ engines [12].

Considering the previously described background, in an attempt to improve the fundamental understanding of the $\mathrm{RCCl}$ combustion process, this paper is focused on describing mixing and combustion processes, as well as pollutant emissions, when diesel/gasoline in-cylinder blending conditions are varied.

The outline of this paper is as follows: In section 2 is detailed the information related with materials and methods. In its first subsection, the experimental facilities used to carry out this research are described. Then, the following subsection consists of the description of the 1-D computational modelling code, used to provide mixing process information. Furthermore, in the third subsection, the experimental methodology and the main operating conditions are detailed. In section 3 there is a discussion about the results obtained from three different parametrical studies, each one on its own subsection. The first one gives an insight of how the port fuel injection of gasoline, as low reactivity fuel, changes combustion behaviour. In the second one, the effects of the evolution from neat diesel conditions to $\mathrm{RCCl}$ combustion, by changing the in-cylinder fuel blending ratio, are analyzed concerning combustion performance and engine-out emissions. In the third study, on the same concern, the discussion is focused on the diesel injection timing. Finally, last section summarizes the main conclusions from this research work.

\section{Materials and methods}

\subsection{Experimental set-up}

All the engine tests were developed following a parametrical scheme on a single cylinder engine, in order to attain a better control of the operating conditions [13]. In this work, a single-cylinder, four-stroke, compression ignition research engine, representative of commercial truck engines, has been used. Detailed basic specifications of the engine are given in Table 1.

Table 1: Main research engine characteristics. 


\begin{tabular}{|l|r|}
\hline Engine type & $\begin{array}{r}\text { Single cylinder, } \\
\text { 4 Stroke cycle, } \\
\text { Direct injection }\end{array}$ \\
\hline Bore x stroke [mm] & $123 \times 152$ \\
\hline Connecting rod length [mm] & 225 \\
\hline Displacement [I] & 1.806 \\
\hline Geometric compression ratio & $14.4: 1$ \\
\hline Number of valves & 4 \\
\hline Valve actuation system & Camless HVA \\
\hline
\end{tabular}

The engine was installed in a fully instrumented test cell, with all the auxiliary facilities required for its operation and control, as is illustrated in Figure 1. Moreover, to achieve stable intake air conditions, a screw compressor supplied the required boost pressure before passing through an air dryer. The air pressure was adjusted within the intake settling chamber, while the intake temperature was controlled in the intake manifold after mixing with EGR. The exhaust backpressure produced by the turbine in the real engine was replicated by means of a valve placed in the exhaust system, controlling the pressure in the exhaust settling chamber.

Low pressure EGR was produced taking exhaust gases from the exhaust settling chamber. Then, once it was filtered by a DPF, its temperature was reduced passing through a heat exchanger. After that, water steam and condensed were separated from gases by means of a centrifugal filter, and resulting gases were passed through a secundary filter. Furthermore, a roots-type supercharger was used in order to provide the external EGR mass flow rate desired. With the aim of lowering the gases temperature increase caused by the supercharger, a second heat exchanger was used before the arrival of the EGR gases to a settling chamber equipped with an electric heater. It was then introduced into the intake pipe, closing the external EGR loop. The temperature regulation was performed upon the EGR-fresh air mixture, by means of a temperature sensor in the intake manifold. Finally, the exact EGR rate was controlled by means of a valve between the EGR settling chamber and the intake pipe.

The determination of the EGR rate was carried out using the experimental measurement of intake and exhaust $\mathrm{CO}_{2}$ concentration. The concentrations of $\mathrm{NOx}, \mathrm{CO}, \mathrm{uHC}$, intake and exhaust $\mathrm{CO}_{2}$, and $\mathrm{O}_{2}$ were measured with specific state-of-the-art analyzers. Smoke emission was measured with a variable sampling smoke meter, providing results directly in FSN (Filter Smoke Number) units that were transformed into dry soot mass emissions by means of the correlation proposed by Christian et al. [iError! No se encuentra el origen de la referencia.].

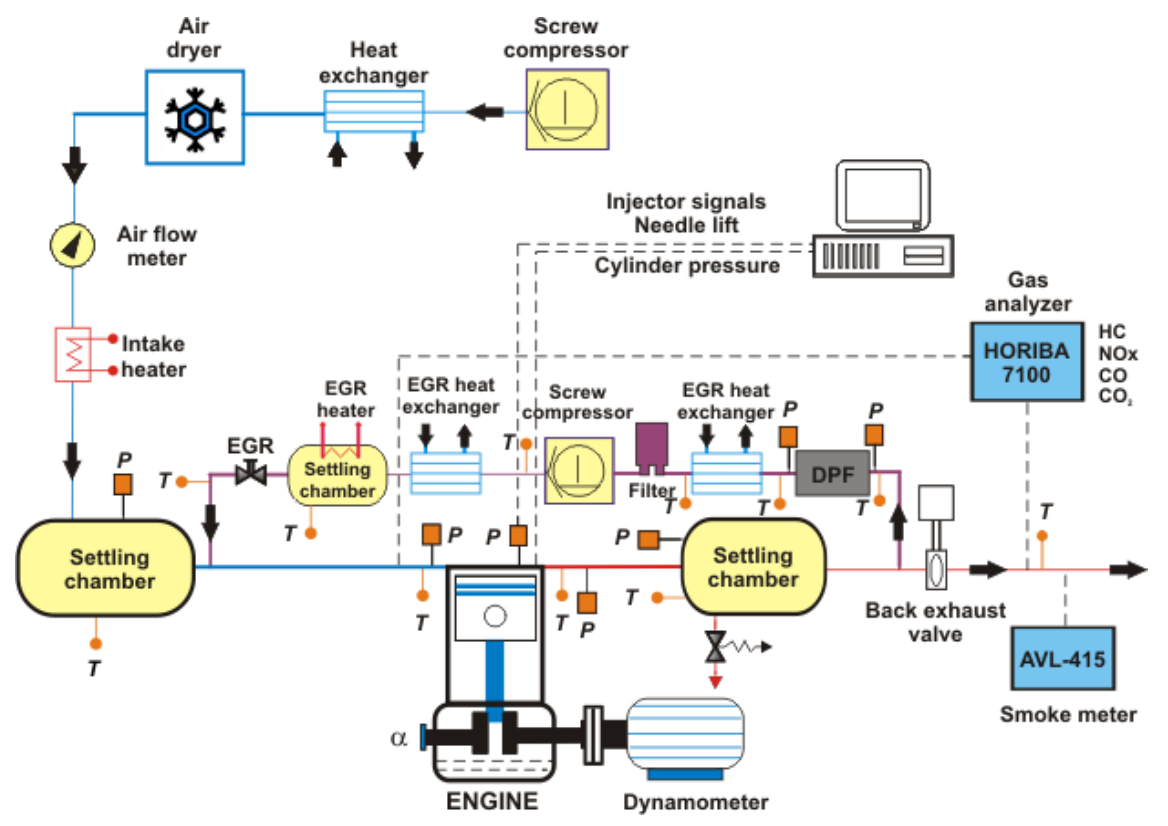

Figure 1: Complete test cell schema. 
Considering the combustion strategy proposed, to carry out the experimental tests commercially available diesel and gasoline $98 \mathrm{ON}$ fuels were selected as high and low reactivity fuels, respectively. Their main properties related with auto-ignition are listed in Table 2.

Table 2: Characteristics of fuels used along the study.

\begin{tabular}{|l|c|c|}
\hline Fuel & Gasoline & Diesel \\
\hline Density [kg/m3] (T=15ㅇ) & 722 & 882 \\
\hline Viscosity [mm2/s] (T=40C) & 0.37 & 2.8 \\
\hline Octane Number [-] & 98 & - \\
\hline Cetane Number [-] & - & 52 \\
\hline Lower heating value [kJ/kg] & 44542 & 42651 \\
\hline
\end{tabular}

To enable RCCI operation the engine was equipped with a double injection system, one for each different fuel used, as is shown in the schema of Figure 2. This injection hardware enables to vary the in-cylinder fuel blending ratio, fuel mixture properties, according with the engine operating conditions [15].

Related to the diesel fuel, the engine was equipped with a common-rail flexible injection hardware which is able to perform up to five injections per cycle; the main characteristic of this hardware is its capability to amplify commonrail fuel pressure for one of the injections (main injection) by means of a hydraulic piston directly installed inside the injector. Moreover, taking into account the diesel injection event shortening due to the port fuel injection of gasoline, a low hydraulic flow nozzle was selected to develop this study. The main characteristics of the nozzle used are: 8 holes with a diameter of $100 \mu \mathrm{m}$ and an included angle between spays of $140^{\circ}$.

Concerning the gasoline injection, an additional fuel circuit was in-house built with a reservoir, a fuel filter, a fuel meter, an electrically driven pump, a heat exchanger and a commercially available port fuel injector (PFI). The mentioned injector was located at the intake manifold and was specified to be able to place all the gasoline fuel into the cylinder during the intake stroke. Consequently, the gasoline injection timing was fixed $10 \mathrm{CAD}$ after the IVO to allow the fuel to flow along $160 \mathrm{~mm}$ length (distance from PFI location to intake valves seats). Accordingly, this set up would avoid fuel pooling over the intake valve and the undesirable variability introduced by this phenomenon.

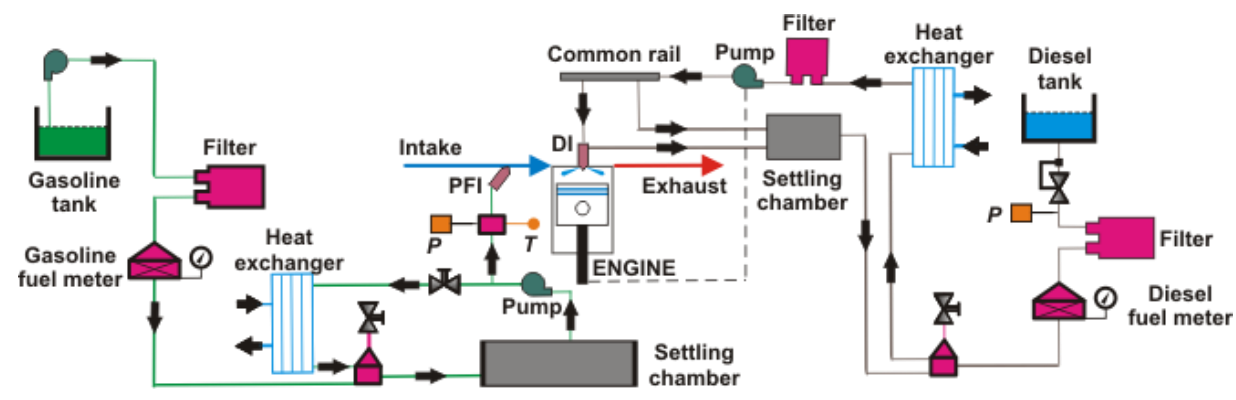

Figure 2: Fuel injection systems scheme.

\subsection{D Computational modelling}

The data collected from the single cylinder engine were used as input for an in-house 1-D spray model, DICOM [16] [17]. The main objective when applying the code is to clarify the mixing process in response to variations of the in-cylinder fuel blending ratio and injection timings.

The specific and necessary inputs for the model are the in-cylinder thermodynamics conditions evolutions (pressure, temperature and density), the jet cone angle and the fuel mass injection rate. In addition to be closer to 
the real ambient conditions, the oxygen mass fraction at IVC and the stoichiometric equivalence ratio (defined as equation 1 shows) are needed to take into account the entrainment of air plus EGR and gasoline, respectively.

$$
\emptyset_{\text {est }}=\frac{1-\emptyset_{G}}{C_{D}+\frac{H_{D}}{4}} \cdot \frac{12 C_{D}+H_{D}}{32} \cdot \frac{1}{1+\frac{Y_{N_{2, a i r}}}{Y_{O_{2, a i r}}}+\emptyset_{G} \cdot \frac{1}{C_{G}+\frac{H_{G}}{4}} \cdot \frac{12 C_{G}+H_{G}}{32}}
$$

Equation 1: Estequiometric equivalence ratio calculation

Then, the model solves the general conservation equations either in a transient or steady formulation for axial momentum and fuel mass in terms of the on-axis (i.e. center line) referred to instantaneous values of velocity, species mass fractions and others.

Physically, the model is based on the fact that the fuel is injected with a uniform radial profile, downstream of the nozzle, momentum exchange of the fuel with the surrounding air leads to increase the width of the spray as the axial distance increases. Radial growth of the spray is determined by the cone angle. Thus, as a typical transient problem, the entire spray domain is divided axially in a certain number of cells that occupy the whole spray cross section, each with a width of $\Delta x$ and, each cell is limited by an inlet (Xi).

To better understand the mixing process conditions at $\mathrm{SoC}$, a specific methodology was carried out with the aim of knowing how the mass fuel was distributed in different equivalence ratios. For each test, considering the data obtained from the experimental work, were determined the Sol and SoC timings. These data provided the calculation time for the 1-D model, because in the computational study the calculation of spray is performed from Sol to SoC.

As a first approach, the 1-D model results consist of a spatial and temporal evolution of different equivalence ratios (from 9 to 0.2 in steps of 0.2). At specific time the information provided by the code is shown in Figure 3 .
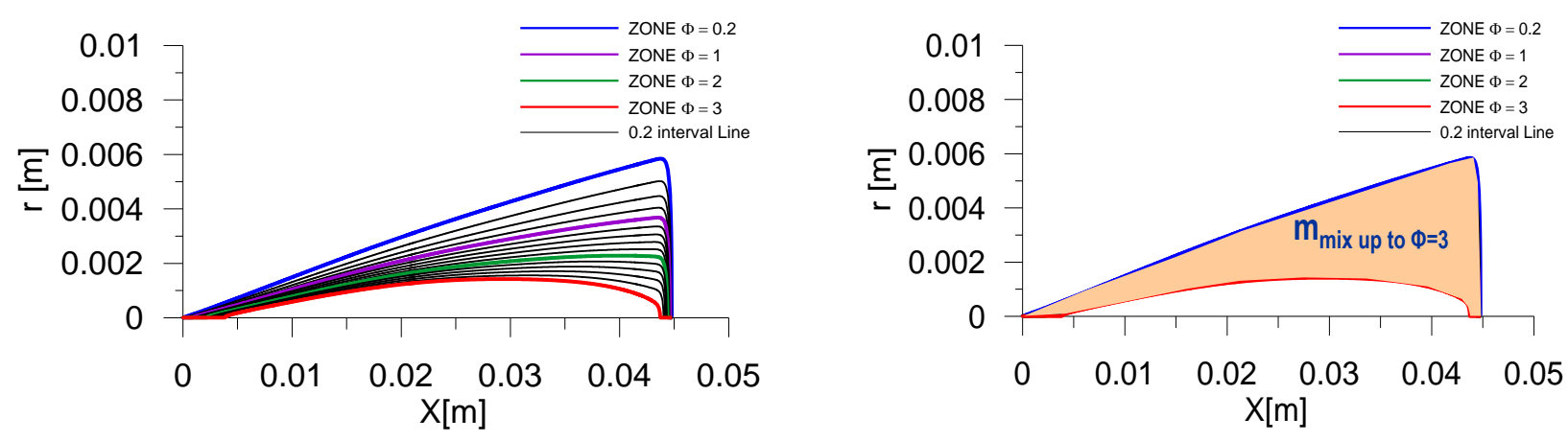

Figure 3: Spatial evolution of spray in 1D model with equivalence ratio iso-lines.

As can be seen in Figure 3, with the results of the 1-D code is possible to extract the iso-lines for the equivalence ratio zones. In addition, the masses mixed up to different equivalence ratios for the entire temporal history of the spray are calculated.

Performing a mathematically processing work, a mass distribution mixed up in 0.2 bins to different $\Phi$ is obtained at experimental SoC. To understand better the methodology, an example is shown in Figure 4. 


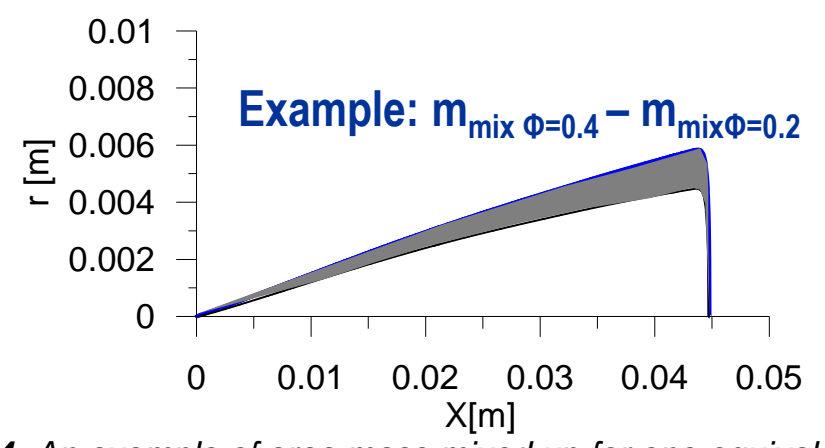

Figure 4: An example of area mass mixed up for one equivalence ratio

Figure 5 shows the result of the methodology used. In this case, bars represent the result of the masses mixed up to different local equivalence ratios and the solid line profile, the envelope of these bars.

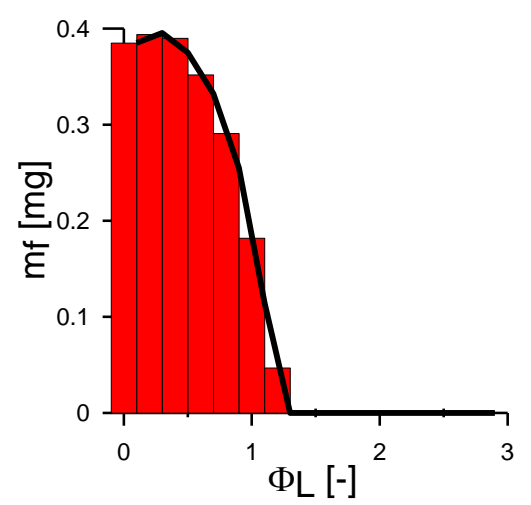

Figure 5: Evolution of procedure to obtain the mass under the local equivalence ratio.

\subsection{Methodology}

As a general methodology, a combined strategy between experiments and 1-D modelling has been carried out for each parametrical study.

Aside from the preliminary study, all the experiments were developed at low-load and medium-speed conditions, coincident with the A25 mode of the European Stationary Cycle for emission certification of heavy-duty diesel engines (fixed $25 \%$ load and $1200 \mathrm{rpm}$ ). In Table 3 appears a summary of the operating conditions that were kept fixed during the experiments. Regarding air management, despite the advantages in terms of fast-motion intake and exhaust valve lift profiles (which reduces gas energy looses), it must be highlighted that the valve settings listed below imply that there is no valve overlap. Due to the very little clearance between the piston and valves, when the piston is close to TDC fast-motion lift impedes the presence of a valve overlap at breathing TDC reducing volumetric efficiency, otherwise valve to piston contact will occur. Moreover, the total injected fuel mass (except in the first study), the intake pressure and the EGR rate were kept fixed providing a global effective equivalence ratio of 0.7 and an intake oxygen mass fraction at IVC of $15.5 \%$. These conditions were selected in order to be able to develop RCCI combustion.

Table 3: Common settings of the tests described.

\begin{tabular}{|c|c|c|c|c|c|c|c|c|c|c|c|}
\hline \multicolumn{4}{|c|}{ GENERAL SETTINGS } & \multicolumn{3}{c|}{ INJECTION SETTINGS } & \multicolumn{3}{|c|}{ VALVES SETTINGS } \\
\hline $\begin{array}{c}\text { Speed } \\
\text { (rpm) }\end{array}$ & $\begin{array}{c}\text { P_IN } \\
(\text { bar) }\end{array}$ & $\begin{array}{c}\text { P_EX } \\
\text { (bar) }\end{array}$ & $\begin{array}{c}\text { T_IN } \\
(\mathbf{(}-\mathbf{C})\end{array}$ & $\begin{array}{c}\text { EGR } \\
\text { (\%) }\end{array}$ & $\begin{array}{c}\text { DI } \\
\text { pressure } \\
\text { (bar) }\end{array}$ & $\begin{array}{c}\text { PFI } \\
\text { pressure } \\
\text { (bar) }\end{array}$ & $\begin{array}{c}\text { Sol } \\
\text { Gasoline } \\
\text { (cad) }\end{array}$ & $\begin{array}{c}\text { IVO } \\
\text { (cad) }\end{array}$ & $\begin{array}{c}\text { IVC } \\
\text { (cad) }\end{array}$ & $\begin{array}{c}\text { EVO } \\
\text { (cad) }\end{array}$ & $\begin{array}{c}\text { EVC } \\
\text { (cad) }\end{array}$ \\
\hline 1200 & 1.35 & 1.15 & 40 & 45 & 900 & 5 & 385 & 375 & 535 & 147 & 347 \\
\hline
\end{tabular}


It is necessary to mention that, to ensure the reliability of the provided results, at every operation point its measurement was repeated three times and a reference point was controlled before every measuring session, in order to guarantee tests repeatability along the study. Moreover, all analyzers, sensors and transducers were calibrated by applying their respective manufacturers recommended methods. In order to give an idea of the error that can be derived from experimental measurements, Table 4 summarizes the accuracy of the instrumentation used in this work.

Table 4: Accuracy of the instrumentation used in this work.

\begin{tabular}{|c|c|c|c|}
\hline Variable measured & Device & $\begin{array}{l}\text { Manufacturer } \\
\text { and model }\end{array}$ & Accuracy \\
\hline In-cylinder pressure & $\begin{array}{l}\text { Piezoelectric } \\
\text { transducer }\end{array}$ & Kistler 6125B & \pm 1.25 bar \\
\hline $\begin{array}{l}\text { Intake/exhaust } \\
\text { pressure }\end{array}$ & $\begin{array}{l}\text { Piezorresistive } \\
\text { transducers }\end{array}$ & Kistler 4045A10 & $\pm 25 \mathrm{mbar}$ \\
\hline $\begin{array}{l}\text { Temperature in } \\
\text { settling chambers and } \\
\text { manifolds }\end{array}$ & Thermocouple & TC direct K Type & $\pm 2.5 \operatorname{deg} C$ \\
\hline $\begin{array}{l}\text { Crank angle, engine } \\
\text { speed }\end{array}$ & Encoder & AVL 364 & \pm 0.02 CAD \\
\hline $\mathrm{NOx}, \mathrm{CO}, \mathrm{HC}, \mathrm{O} 2, \mathrm{CO} 2$ & Gas analyzer & $\begin{array}{l}\text { HORIBA Mexa } \\
\text { 7100DEGR }\end{array}$ & $4 \%$ \\
\hline FSN & Smoke meter & AVL 415 & \pm 0.025 FSN \\
\hline $\begin{array}{l}\text { Gasoline/diesel fuel } \\
\text { mass flow }\end{array}$ & Fuel balances & AVL 733S & $\pm 0.2 \%$ \\
\hline Air mass flow & Air flow meter & Elster RVG G100 & $\pm 0.1 \%$ \\
\hline
\end{tabular}

At each engine operation point, the in-cylinder pressure traces from a piezo-electric transducer were recorded during 50 consecutive engine cycles in order to compensate for dispersion in engine operation. The remarked number of cycles was chosen by means of a preliminary study [18]. Then, the recorded values of in-cylinder pressure were processed by means of a combustion diagnosis code CALMEC [19] [20]. Valuable information can be extracted, such as the heat release, the rate of heat release (RoHR) and the unburned gases temperature, which is one basic input to the adiabatic flame temperature (Tad) calculation. Tad represents the temporal evolution of the maximum temperature overall the combustion chamber (considering unburned gases and products of oxidation). It has been calculated with the assumption of constant pressure at each step of calculation, adiabatic burning of the fuels/air mixture and considering a conventional chemical equilibrium model, with 13 species into in the reaction, following the scheme proposed by Way [21].

Afterwards, a combination of experimental measurements and results from the combustion diagnosis code were used as input for the 1-D spray model for the calculation of the evolution of the local equivalence ratio after the Sol and before the SoC, as is detailed in the previous subsection.

\section{Results and discussion}

\subsection{Effects of adding port-injected gasoline to neat diesel combustion}

Regarding the literature, varying fuel reactivity seems to be a suitable solution to $\mathrm{HCCl}$ combustion dilemma. Thus, a preliminary experimental study was performed in order to analyze the role played by the burning of gasoline in the combustion behaviour. In this study the direct injection of diesel fuel was kept constant, while the total amount of injected fuel was increased by adding gasoline through the intake pipe. Particular operating conditions of these tests are given in Table 5.

Table 5: Engine operating conditions, starting from neat diesel combustion and adding port-injected gasoline. 


\begin{tabular}{|c|c|c|c|c|c|c|c|}
\hline $\begin{array}{l}\text { Speed } \\
\text { [rpm] }\end{array}$ & $\begin{array}{l}\text { mf_total } \\
\text { [mg/str] }\end{array}$ & $\begin{array}{c}\text { Diesel Sol } \\
\text { [cad } \\
\text { aTDC] }\end{array}$ & \multicolumn{2}{|c|}{$\begin{array}{c}\text { mf_inj } \\
\text { Diesel } \\
\text { [mg/str] }\end{array}$} & \multicolumn{2}{|c|}{$\begin{array}{c}\text { mf_inj } \\
\text { Gasoline } \\
\text { [mg/str] }\end{array}$} & $\begin{array}{c}\text { EGR_ext } \\
\text { [\%] }\end{array}$ \\
\hline \multirow{4}{*}{1200} & 24.5 & \multirow{4}{*}{-24} & 24.5 & $100.00 \%$ & 0 & $0.00 \%$ & \multirow{4}{*}{5} \\
\hline & 42 & & 24.5 & $58.33 \%$ & 17.5 & $41.67 \%$ & \\
\hline & 49.2 & & 24.5 & $49.80 \%$ & 24.7 & $50.20 \%$ & \\
\hline & 53.2 & & 24.5 & $46.05 \%$ & 28.7 & $53.95 \%$ & \\
\hline
\end{tabular}

\subsubsection{Mixing and combustion process}

Instantaneous traces of RoHR are presented in Figure 6 coupled with their corresponding simulated diesel injection rates. Looking to the neat diesel combustion (red trace) it shows cool flame reactions, followed by the main energy release stage (premixed burning) and a short tail of late combustion. When the diesel fuel is injected into a gasoline-air atmosphere, it gets vaporized creating non-uniform reactivity stratification in the combustion chamber. Therefore, combustion behaviour changes, as Figure 6 shows. Firstly, low temperature reactions, cool flames [22], appear as in the neat diesel case promoted by the diesel injection. Afterwards, the auto-ignition of the high reactivity zones (diesel vaporized plus gasoline entrained) results in higher peak of high temperature heat release due to the increase of fuel mass burning in this premixed stage. And finally, the previous multi site combustion (from the 8 fuel jets) leads to multiple propagation flames through the low reactivity zones. That is why the previously named as late combustion (from neat diesel conditions) is enhanced and appears as a second stage of high temperature heat release. Thus, $\mathrm{RCCl}$ combustion is staged according with the mixture reactivity stratification, from the higher to the lower.

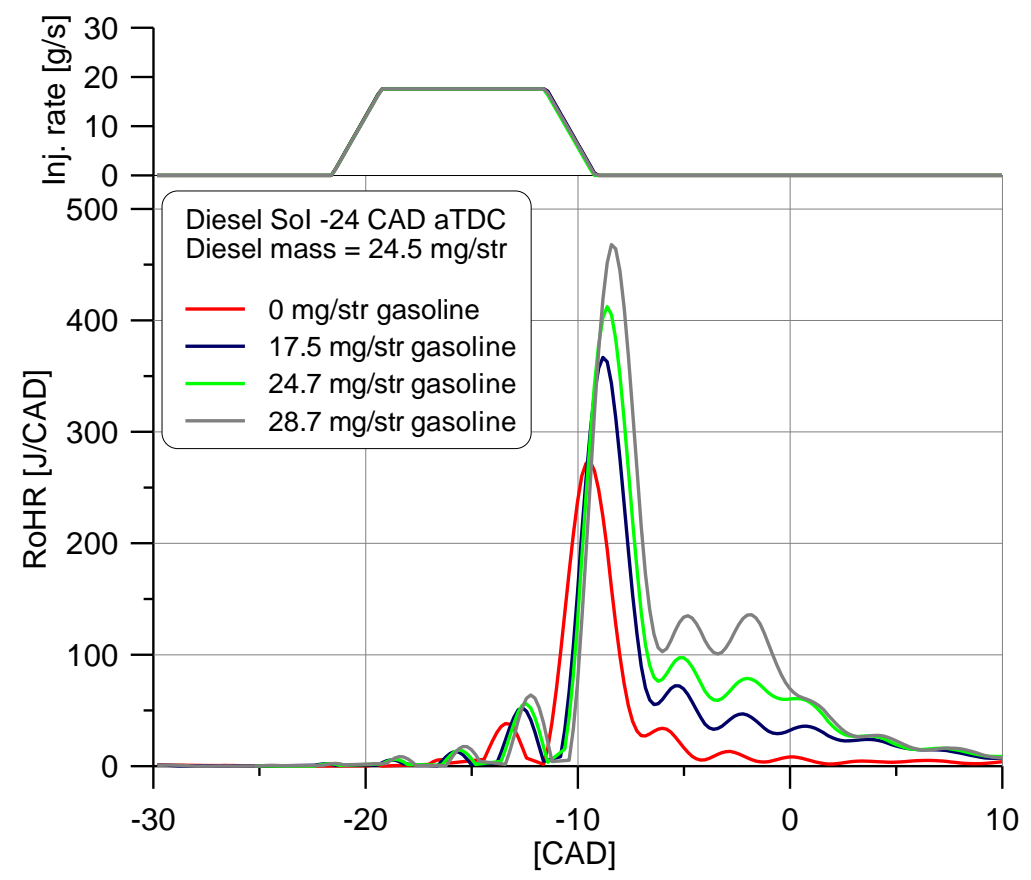

Figure 6: Simulated diesel injection rate and RoHR results.

In order to understand better the experimental results previously discussed, calculations with in-house 1-D model have been performed. The main objective of those simulations is to provide information about the mixing process, mainly, the local equivalence ratio at SoC conditions will be studied for the different tests detailed in Table 5. It should be noted that, although iso-octane and dodecane are the chosen surrogates for the gasoline and diesel fuels, they will be named as gasoline and diesel with the aim of simplifying the analysis nomenclature.

Figure 7 presents the mass distribution mixed up to different equivalence ratios calculated at experimental SoC for neat diesel and different diesel-gasoline in-cylinder blending ratios, at -24 CAD aTDC of diesel injection timing and using a $45 \%$ of EGR rate. In the mentioned figure is clearly highlighted how increasing the amount of gasoline 
port-injected enhances the mixture stratification, because there exists more diesel fuel at higher local equivalence ratios and less at lower local equivalence ratios, when the high temperature heat release starts. This fact agrees with the enlargement of the second stage of energy release seen in Figure 6. Considering the homogeneous charge of gasoline (low reactivity fuel), the reactivity stratification will be leaded by the equivalence ratio stratification of the diesel fuel (high reactivity fuel), which is enhanced by adding port-injected gasoline.

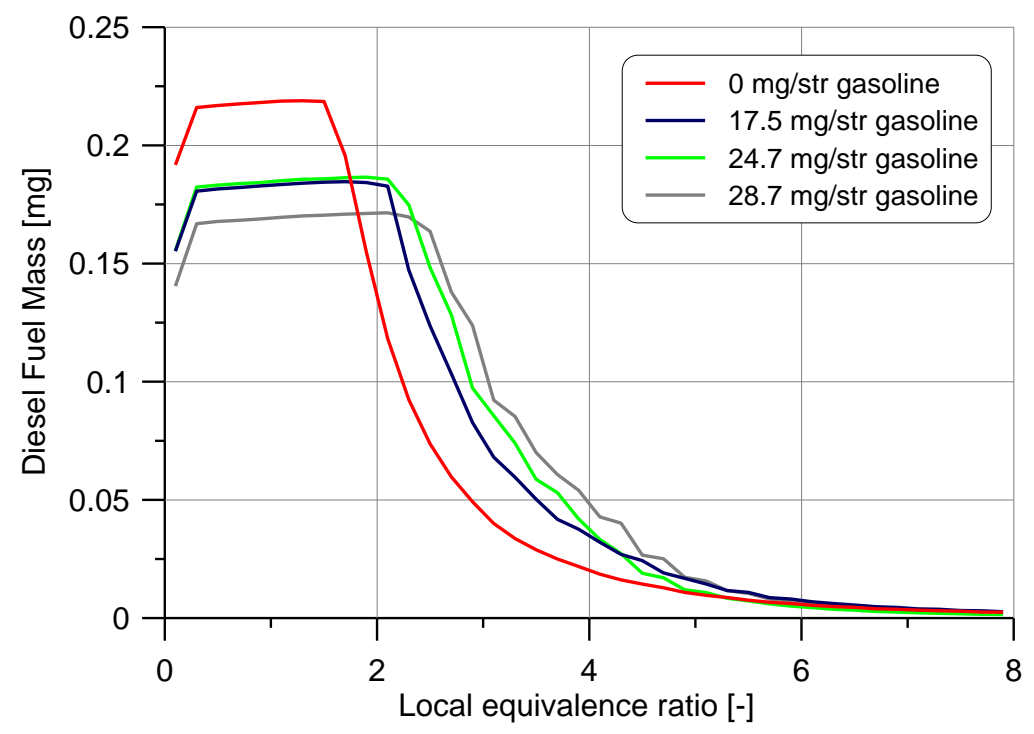

Figure 7: Diesel mass under the local equivalence ratio at the SoC.

\subsection{Effects of varying the in-cylinder fuel blending ratio on $\mathrm{RCCl}$ combustion}

Once the effects of adding a gasoline port-injection to neat diesel combustion have been described in terms of mixing and combustion process, this study is focused on the effects of varying global fuel reactivity over combustion performance and engine-out emissions. Starting from neat diesel combustion, the amount of diesel fuel injected was reduced up to the $10 \%$ of the total fuel mass, and the amount of gasoline was increased keeping the total amount of fuel injected constant. Those tests were developed at a constant engine speed (1200 rpm), a fixed diesel injection timing (-24 CAD aTDC) and a fixed rate of EGR (45\%). Particular operating conditions of these tests are given in Table 6.

Table 6: Tests from the study of the in-cylinder fuel blending ratio.

\begin{tabular}{|c|c|c|c|c|c|c|c|}
\hline $\begin{array}{l}\text { Speed } \\
\text { [rpm] }\end{array}$ & $\begin{array}{l}\text { mf_total } \\
\text { [mg/str] }\end{array}$ & $\begin{array}{c}\text { Diesel Sol } \\
\text { [cad } \\
\text { aTDC] }\end{array}$ & \multicolumn{2}{|c|}{$\begin{array}{c}\text { mf_inj } \\
\text { Diesel } \\
\text { [mg/str] }\end{array}$} & \multicolumn{2}{|c|}{$\begin{array}{c}\text { mf_inj } \\
\text { Gasoline } \\
\text { [mg/str] }\end{array}$} & $\begin{array}{c}\text { EGR_ext } \\
\text { [\%] }\end{array}$ \\
\hline \multirow{5}{*}{1200} & \multirow{5}{*}{70} & \multirow{5}{*}{-24} & 70 & $100 \%$ & 0 & $0 \%$ & \multirow{5}{*}{45} \\
\hline & & & 52.5 & $75 \%$ & 17.5 & $25 \%$ & \\
\hline & & & 35 & $50 \%$ & 35 & $50 \%$ & \\
\hline & & & 17.5 & $25 \%$ & 52.5 & $75 \%$ & \\
\hline & & & 7 & $10 \%$ & 63 & $90 \%$ & \\
\hline
\end{tabular}

\subsubsection{Mixing and combustion process}

RoHR results from tests detailed in Table 6 are presented in Figure 8, coupled with their corresponding calculated adiabatic flame temperatures. On the other hand, Figure 9 presents the mass distribution mixed up to different equivalence ratios calculated at experimental SoC. Looking to Figure 8, the neat diesel combustion (red trace) shows cool flame reactions and a peak of premixed burn, followed by a diffusion stage, in which injection and combustion events are overlapped. Then, as a conventional diesel combustion, after the Eol there is a stage of late burning. 
As the diesel/gasoline in-cylinder blending ratio is reduced from $100 / 0 \%$ to $50 / 50 \%$, the ignition delay increases due to the global lowering of fuel reactivity. Accordingly, the diesel jet has more time to entrain air and gasoline, and afterwards, the premixed stage of combustion shows higher peaks of heat released. At these conditions, SoC appears before the Eol, so the longer ignition delay implies there appear richer local equivalence ratios at the SoC, as Figure 9 shows.

An important change of the combustion behaviour appears when the in-cylinder diesel/gasoline blending ratio is reduced from $50 / 50 \%$ to $25 / 75 \%$. Like in previous ICFB ratios tested, the lower global fuel reactivity implies longer ignition delays. Furthermore, the shorter diesel injection event is able to entrain fewer amounts of air and gasoline before its auto-ignition. Accordingly, as is shown in the grey trace of Figure 8, there appears a first peak of heat released that is lowered, compared with previous cases. This is the premixed burn of most of the diesel fuel injected and its corresponding entrained air and gasoline. After this first HTHR stage, a stratified mixture of gasoline, air and diesel fuel (that did not burn before) burns as a multiple flame propagation (second HTHR stage), onset by the raise in pressure and temperature from the previous premixed burn. This two-staged combustion shows a squared shape with lower maximum peaks of heat release and a proper combustion phasing.

Moreover, if the diesel/gasoline ratio is further reduced, from $25 / 75 \%$ up to $10 / 90 \%$ the combustion process is highly worsened. First of all, it should be kept in mind that this ICFB has the lowest global reactivity tested in this research. In addition, the diesel injection event is too short and the energy given by the diesel injection is not enough to onset multiple propagation flames. Both conditions, added to the low intake oxygen mass fraction $(15.5 \%)$, deal with a long ignition delay and an over-mixing of the high reactivity fuel (worsened reactivity stratification across the cylinder). Concerning the equivalence ratio stratification, looking to Figure 10, the long ignition delay coupled with the fact that the injection rate has finished much before the SoC, imply the appearance of the leanest local equivalence ratio from all tests. At the end, those conditions imply an important worsening in combustion efficiency, which agrees with too long and less energetic black RoHR trace of Figure 8.
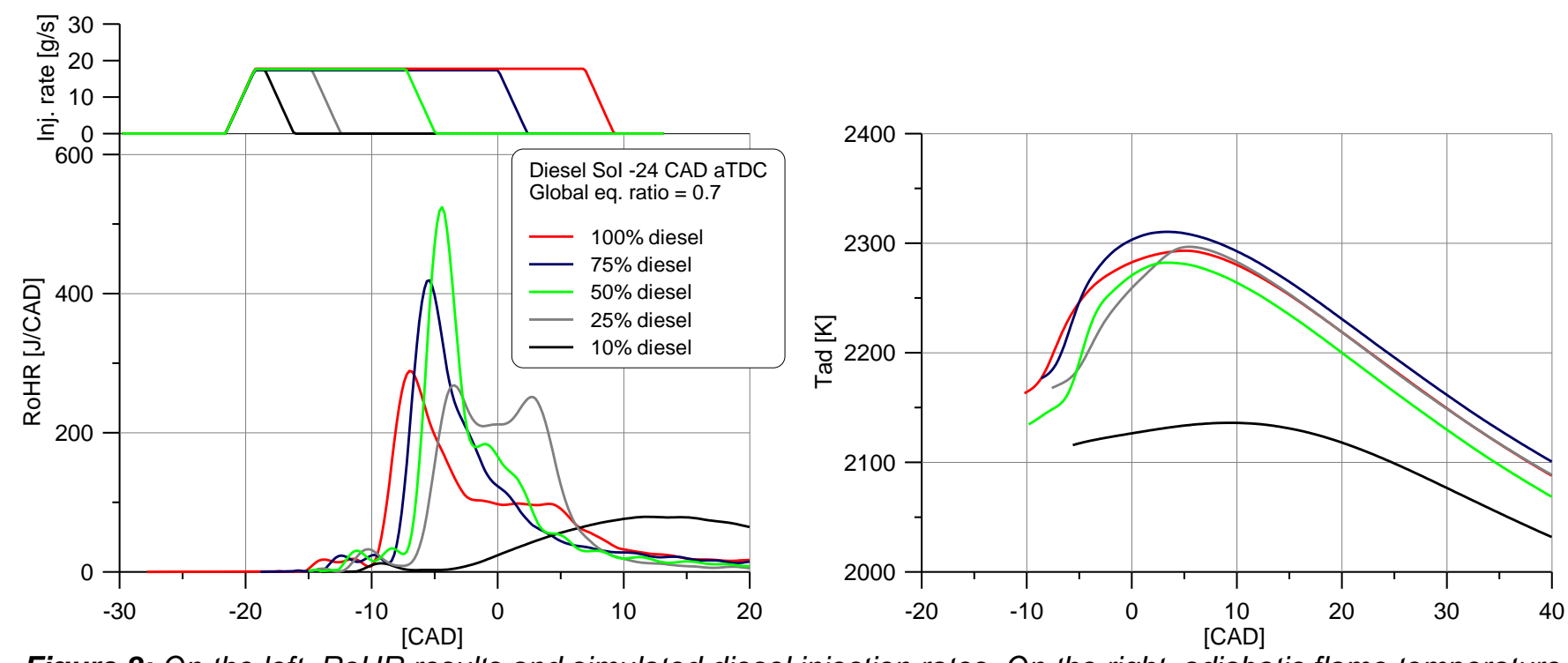

Figure 8: On the left, RoHR results and simulated diesel injection rates. On the right, adiabatic flame temperature calculations 


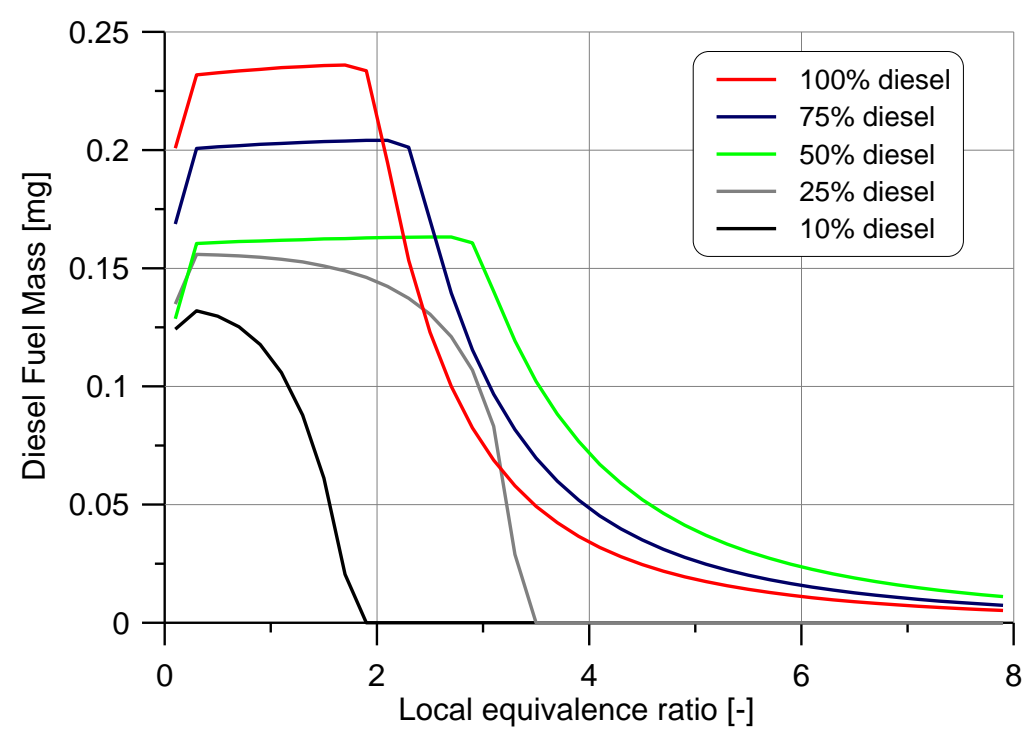

Figure 9: Diesel mass under the local equivalence ratio at the SoC.

\subsubsection{Pollutant emissions}

Figure 10 shows the evolution of the main engine-out emissions as the ICFB ratio is modified, from neat diesel conditions up to $10 \%$ diesel / $90 \%$ gasoline. According with the combustion behaviour variation detailed in section 3.2.1, the engine-out emissions also vary their trends, so this analysis follows the same structure.

The neat diesel case burns as a conventional diffusive combustion. Consequently, it shows low levels (close to EURO VI limits) of $\mathrm{CO}$, uHC; medium levels of NOx emissions; and high levels of soot emissions. As the diesel/gasoline in-cylinder blending ratio is reduced from $100 / 0 \%$ to $50 / 50 \%$, soot emissions are strongly reduced due to longer ignition delay and the increase of the low reactivity fuel amount (shorter fuel molecules that lower soot formation). Longer ignition delays also help on a slight reduction of NOx emissions. However, as global reactivity is lowered, oxidation processes are worsened and $\mathrm{CO}$ and $\mathrm{UHC}$ emissions increase.

The combustion behaviour variation observed in Figure 8 as the diesel/gasoline ICFB ratio was swept from $50 / 50 \%$ to $25 / 75 \%$, only reported a noticeable change in terms of NOx emissions trend. The squared RoHR implies shorter combustion events, but with extended duration of its maximum peak of heat released. As a consequence, the maximum adiabatic flame temperatures are higher and NOx emissions increase. On the other hand, it also contributes to improve $\mathrm{CO}$ oxidation processes. However, uHC are not reduced. It means that, the increase of low reactivity fuel amount across the cylinder and at cold regions has a stronger effect (gasoline near the wall and the crevices is difficult to burn [23]) than the mentioned enhancement of the oxidation processes.

As was described in section 3.2.1, if the diesel/gasoline ratio is reduced from $25 / 75 \%$ up to $10 / 90 \%$ the combustion process gets highly worsened. Results in Figure 10 in terms of uHC and $\mathrm{CO}$ emissions confirm this fact with their important increase. Furthermore, the deterioration of the combustion process implies lower adiabatic flame temperatures, as is shown in Figure 8. Thus, the lean local equivalence ratios and the low adiabatic flame temperatures agree with the low levels of soot and NOx emissions shown in Figure 10. 


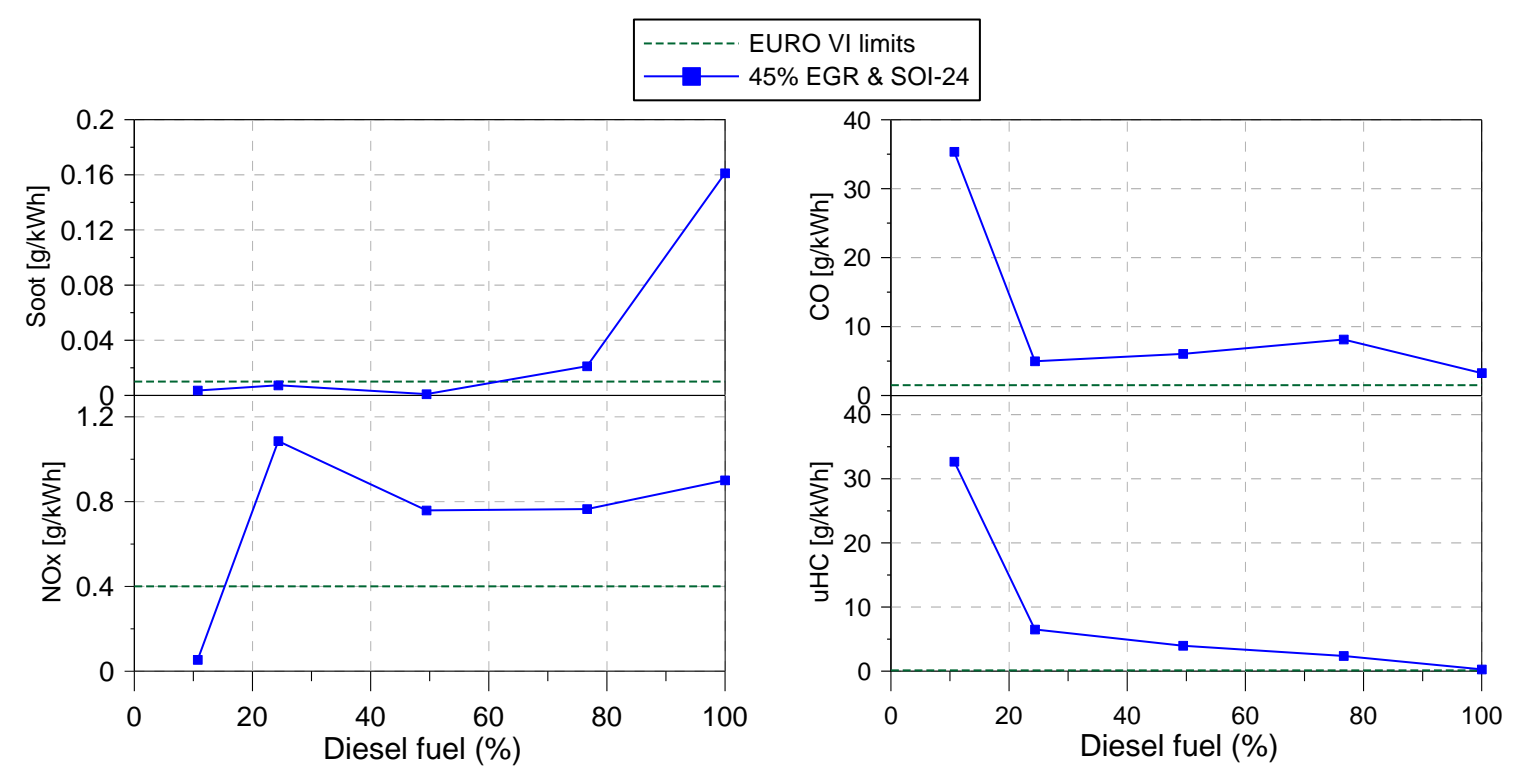

Figure 10: Results in terms of pollutant emissions.

\subsection{Effects of injection timing on $\mathrm{RCCl}$ combustion}

The present study is focused on the analysis of the effects of high reactivity fuel injection timing, in terms of mixing-combustion process and engine-out emissions. On this concern, the diesel Sol has been swept from - 15 to -30 CAD aTDC by 3 CAD steps. Those tests were performed at two different ICFB ratios $(25 \% / 75 \%$ and $35 \% / 65 \%$ diesel/gasoline percentages), at a fixed engine speed (1200 rpm) and a fixed rate of EGR (45\%). Particular operating conditions of these tests are given in Table 7.

Table 7: Tests from the study of the diesel injection timing.

\begin{tabular}{|c|c|c|c|c|c|c|c|}
\hline $\begin{array}{c}\text { Speed } \\
\text { [rpm] }\end{array}$ & $\begin{array}{l}\text { mf_total } \\
\text { [mg/str] }\end{array}$ & $\begin{array}{c}\text { Diesel Sol } \\
\text { [cad } \\
\text { aTDC] }\end{array}$ & & & & $\begin{array}{l}\text { inj } \\
\text { line } \\
\text { str] }\end{array}$ & $\begin{array}{c}\text { EGR_ext } \\
\text { [\%] }\end{array}$ \\
\hline \multirow{2}{*}{1200} & \multirow{2}{*}{70} & $\begin{array}{c}\text { From - } 15 \\
\text { to }-30 \\
(\Delta=3 \text { CAD })\end{array}$ & 17.5 & $25 \%$ & 52.5 & $75 \%$ & \multirow{2}{*}{45} \\
\hline & & $\begin{array}{c}\text { From }-15 \\
\text { to }-30 \\
(\Delta=3 \text { CAD })\end{array}$ & 24.5 & $35 \%$ & 45.5 & $65 \%$ & \\
\hline
\end{tabular}

\subsubsection{Mixing and combustion process}

Like in the previous section, RoHR results from tests detailed in Table 7 are presented in Figures 11 and 12 , coupled with their corresponding calculated adiabatic flame temperatures. In addition, Figure 13 presents the mass distribution mixed up to different equivalence ratios calculated at experimental SoC.

RoHR results shown in Figures 11 and 12 confirm that $\mathrm{RCCl}$ combustion is a staged process, according to reactivity stratification. Furthermore, combustion stages are strongly influenced by the diesel injection timing. At the most delayed injection timing, the initial stage of HTHR is a sharp peak in which takes place the premixed burn of most diesel fuel and the entrained air-gasoline. Afterwards, the reactivity stratification across the cylinder helps the flame propagation through the lean mixture zones, at the second stage of heat release. Looking to Figure 13, this behaviour is justified by a wider range of local equivalence ratios at SoC. However, as the diesel Sol is advanced, the local equivalence ratio stratification is reduced (and also the reactivity stratification) because of the increase of the ignition delay. This fact implies an important change on the combustion behaviour. The initial stage of combustion stills being premixed but its maximum peak of heat released gets lowered. Moreover, the second stage of heat release starts as multiple propagation flames which lead to generate the appropriate 
conditions for several auto-ignition sites (that could be stated as a third combustion stage). Therefore, the burning of the lower reactivity mixture gets sharper and shorter as is clearly shown in Figure 11, attaining a short and square-shaped RoHR at most advanced injection conditions.

With the aim to analyze how the ICFB ratio affects combustion performance while the diesel injection timing is swept, results in Figure 11 (25/75\% diesel/gasoline ratio) are compared with results in Figure 12 (35/65\% diesel/gasoline in-cylinder blending ratio). In both scenarios, combustion behaviour vary as was explained in the previous paragraph, increasing the ignition delay and shortening the combustion duration mainly by enhancing the second combustion stage, as the injection timing is advanced. However, results in Figure 12 do not show the lowering of the first peak of heat released either the expected squared RoHR shape, at -30 CAD aTDC. Results on the right of Figure 13 (ICFB: 35/65\%) reflect that there is more diesel fuel mass (higher local fuel reactivity) at the same equivalence ratio than in the case of ICFB $25 / 75 \%$. Thus, in order to achieve the favourable squared RoHR it is necessary to use lower global fuel reactivity blends and advanced injection timings to enable the appearance of low auto-ignition sites in the low reactivity regions.
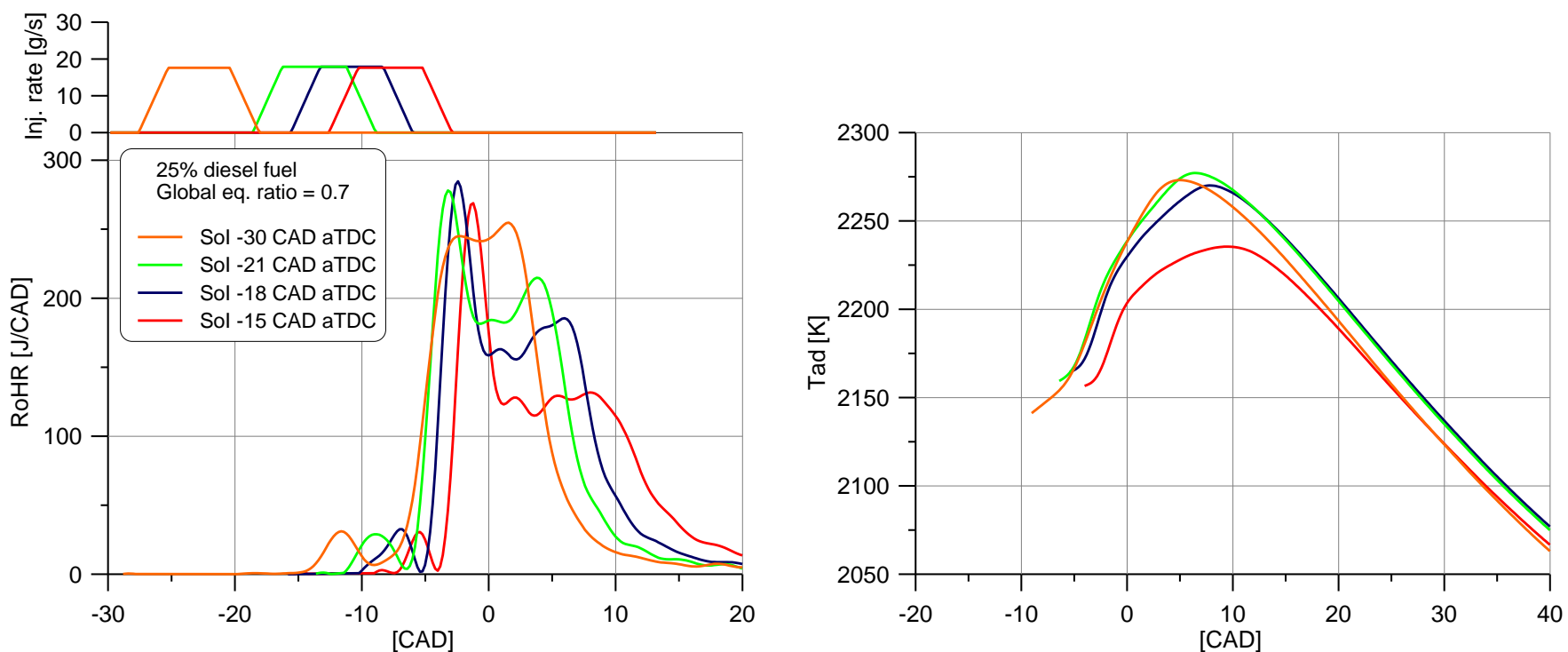

Figure 11: On the left, RoHR results and simulated diesel injection rates. On the right, adiabatic flame temperature calculations. Diesel/gasoline ratio $25 / 75 \%$. Not all of tests were plotted for clarity.
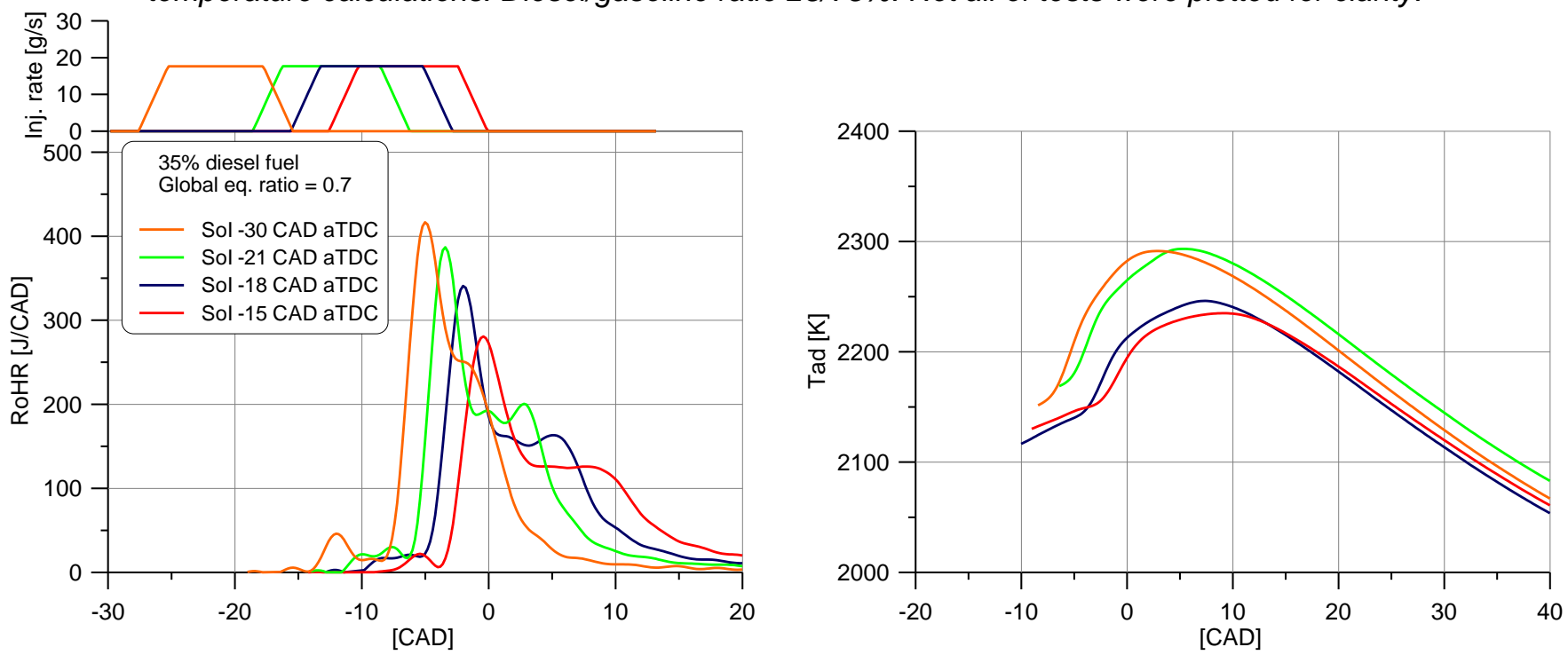

Figure 12: On the left, RoHR results and simulated diesel injection rates. On the right, adiabatic flame temperature calculations. Diesel/gasoline ratio 35/65\%. Not all tests were plotted for clarity. 

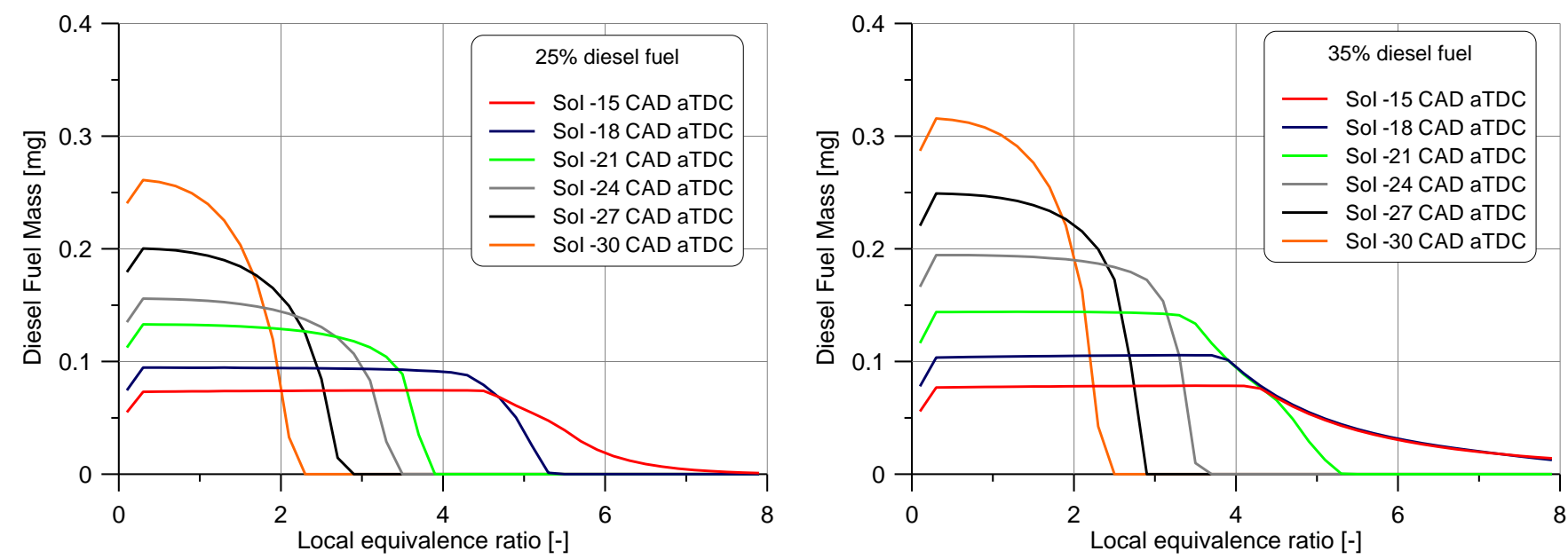

Figure 13: Diesel mass under the local equivalence ratio at the SoC. On the left, for $25 / 75 \%$ and on the right for $35 / 65 \%$ diesel/gasoline in-cylinder blending ratio.

\subsubsection{Pollutant emissions}

Figure 14 shows the evolution of the main pollutant emissions as the diesel Sol is swept, for two different ICFB ratios. According to the variation of the combustion behaviour described in the previous sub-section, the engineout emissions are analysed at to two different scenarios: delayed (from -15 to -24 CAD aTDC) and advanced conditions (from -24 to -30 CAD aTDC). Focusing on 25\%/75\% diesel/gasoline blend at delayed conditions, Figure 14 shows that NOx and soot increase while $\mathrm{uHC}$ and $\mathrm{CO}$ are reduced, as the diesel Sol is advanced. This is due to the fact that the peak of premixed burn increases and also does the maximum adiabatic flame temperature, as is shown in Figure 11. In addition, the shorter ignition delay of delayed injection timings implies the richer local equivalence ratios, as is shown in Figure 13. In this sense, high adiabatic flame temperatures and rich local equivalence ratios lead to increase NOx and soot formation, respectively. By contrast, those high temperatures contribute to improve oxidation processes and to reduce $\mathrm{CO}$ and $\mathrm{uHC}$ emissions. On the other hand, when focusing on the same ICFB at advanced injection conditions, NOx are lowered while uHC and CO are slightly increased, as the diesel Sol is advanced. These opposite trends appear because of the leaner local equivalence ratios, the lower peak of heat released and the lower maximum adiabatic flame temperatures.

How the ICFB ratio affects to engine-out emissions as the diesel injection timing is swept, is shown in Figure 14 (comparing blue and red traces for $25 / 75 \%$ and $35 / 65 \%$ diesel/gasoline ratios, respectively). Both ICFB show the same trends, except for NOx emissions at advanced conditions. At those conditions, the red trace decreases while the blue one keeps increasing. The main reason is because higher global reactivity fuel blends need longer ignition delays to enhance local reactivity stratification across the cylinder, lower the maximum peak of heat released and also the adiabatic flame temperatures. In addition, the $35 / 65 \%$ diesel/gasoline ICFB has more diesel fuel at the same local equivalence ratio, than the $25 / 75 \%$, which contributes to increase soot emissions. In terms of $\mathrm{uHC}$ emissions, the lower global reactivity fuel blend is near 2 glkWh above the other one, whatever the injection timing. Higher uHC emissions from higher gasoline content are resulted from the crevice effect like the top-land crevice, where fuel is more difficult to be burned. 


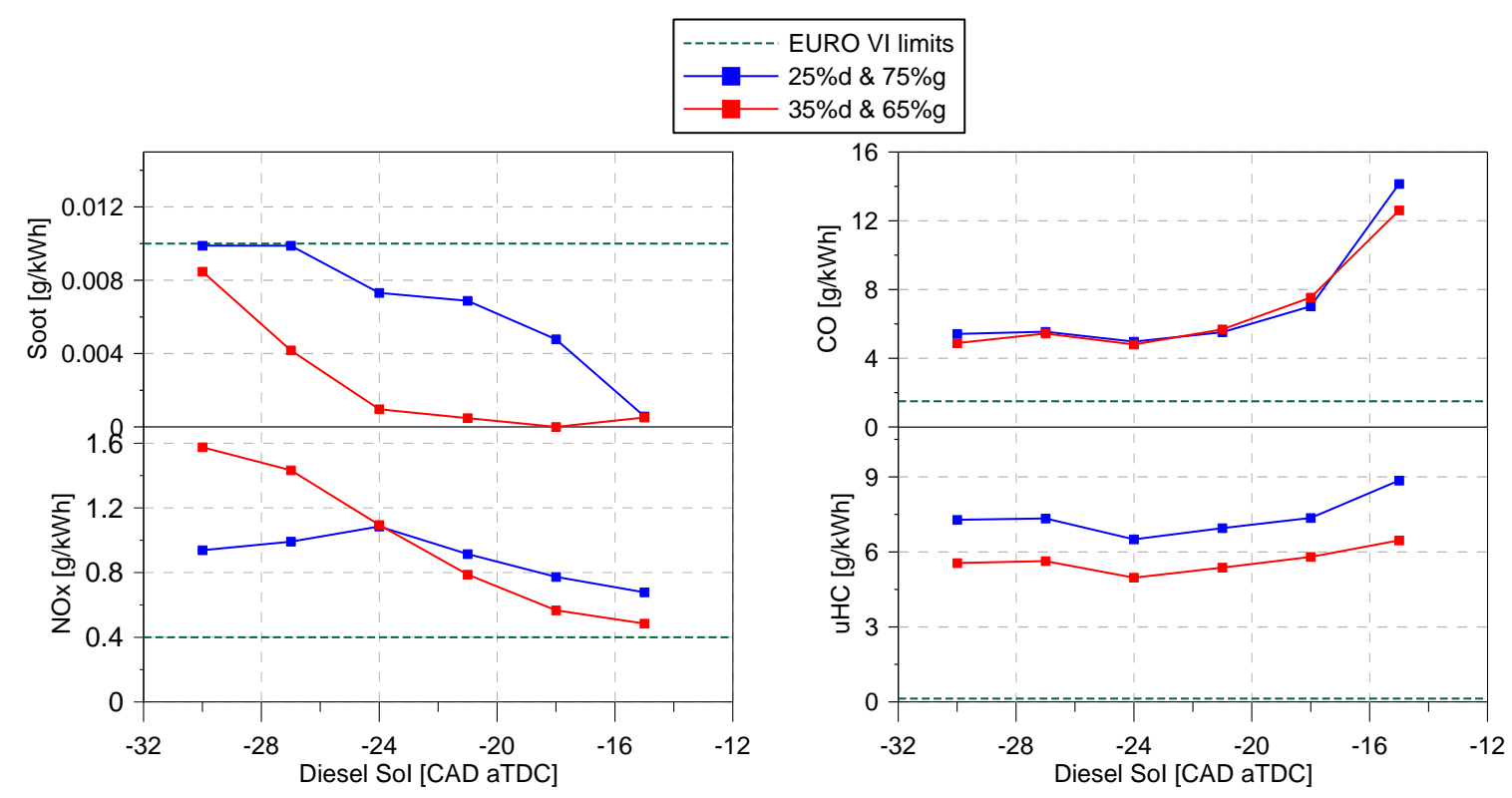

Figure 14: Results in terms of pollutant emissions.

\section{Conclusions}

A detailed investigation has been performed using a heavy-duty $\mathrm{Cl}$ engine, operated at low load conditions and fuelled by port-injected gasoline and in-cylinder direct-injected diesel fuel. This work was focused on mixing combustion processes, and its influence over engine-out emissions. On this concern, 1-D spray modelling was used to calculate the evolution of the local equivalence ratio after the Sol and up to the SoC. The most relevant conclusions are:

- $\mathrm{RCCl}$ resulted in a staged combustion process controlled by the mixture reactivity stratification. Firstly takes place the auto-ignition of the premixed diesel, air and gasoline mixtures (high local reactivity zones). Then, the multi site temperature and pressure raise leads to multiple propagation flames through the low reactivity zones across the combustion chamber. Moreover, if the appropriate conditions are reached (temperature, pressure, equivalence ratio and reactivity distribution), the previous propagation flames deal with the generation of several auto-ignition sites.

- As the in-cylinder fuel blending ratio is varied towards lower global reactivity blends (up to $25 / 75 \%$ diesel/gasoline ratio), the ignition delay gets longer and the fuel reactivity stratification is improved. That implies a premixed stage of combustion slightly lowered and a flame propagation enhanced, shortening combustion duration.

- As the diesel injection timing is advanced, the fuel mixture gets better stratified and less zones of low local reactivity exist across the cylinder. It implies the lowering of the first peak of HTHR and the enhancement of the second one.

- This combustion strategy, reducing the global fuel reactivity and advancing the diesel injection timing, resulted in an efficient "heat-to-work" conversion due to the squared and well timed heat release law achieved.

- On the plus side, $\mathrm{RCCl}$ combustion is able to produce an important reduction in soot and NOx emissions, with respect to neat diesel combustion, showing attainable EURO VI emission limits. On the down side, high levels of $\mathrm{CO}$ and $\mathrm{uHC}$ were measured, mainly due to the crevice effect like the top-land crevice, where low reactivity fuel is more difficult to be burned.

The results of this work show that $\mathrm{RCCl}$ combustion is a promising way to meet future emissions regulations, without expensive after-treatment systems. However, further work is needed to attain a combustion concept useful for the whole engine operating range. 


\section{Acknowledgments}

The authors would like to thank VOLVO Group Trucks Technology for supporting this research.

\section{References}

1. Yanagihara H., Sato Y. and Minuta J., "A simultaneous reduction in NOx and soot in diesel engines under a new combustion system (Uniform Bulky Combustion System -UNIBUS)", 17th International Vienna Motor Symposium, pp 303-314, 1996, Austria.

2. Kimura S., Aoki O., Ogawa H., Muranaka S. and Enomoto Y., "New Combustion Concept for Ultra-Clean and High-Efficiency Small DI Diesel Engines," SAE Technical Paper 1999-01-3681, 1999.

3. Akagawa H., Miyamoto T., Harada A., Sasaki S., Shimazaki N., Hashizume T. and Tsujimura K., "Approaches to Solve Problems of the Premixed Lean Diesel Combustion," SAE Technical Paper 1999-01-0183, 1999.

4. Kimura S., Aoki S., Kitahara Y., Aiyoshizawa E. Ultra-clean combustion technology combining a lowtemperature and premixed combustion concept for meeting future emission standards. SAE International, SAE 2001-01-0200, 2001.

5. Fang Q., Fang J., Zhuang J., Huang Z.. "Influence of pilot injection and exhaust gas recirculation (EGR) on combustion and emissions in a HCCI-DI combustion engine." Applied Thermal Engineering, Volume 48, 15 December 2012, Pages 97-104.

6. Kiplimo R., Tomita E., Kawahara N. and Yokobe S.. "Effects of spray impingement, injection parameters, and EGR on the combustion and emission characteristics of a PCCI diesel engine." Applied Thermal Engineering, Volume 37, May 2012, Pages 165-175.

7. Mingfa Y., Zhaolei Z. and Haifeng L., "Progress and recent trends in homogeneous charge compression ignition $(\mathrm{HCCl})$ engines". Progress in Energy and Combustion Science, Volume 35, Issue 5, October 2009, Pages 398-437

8. Keeler B. and Shayler P.J., "Constraints on Fuel Injection and EGR Strategies for Diesel PCCI-Type Combustion". SAE 2008-01-1327.

9. Hildingsson L., Johansson B., Kalghatgi G.T. and Harrison A.J. "Some effects of fuel autoignition quality and volatility in premixed compression ignition engines". SAE 2010-01-0607.

10. Kokjohn S.L., Hanson R.M., Splitter D.A, and Reitz R.D. "Experiments and modeling of Dual-Fuel HCCl and $\mathrm{PCCl}$ combustion using in-cylinder fuel blending" SAE international journal of engines, 2009-01-2647, 2009.

11. Hanson R.M., Kokjohn S.L., Splitter D.A., and Reitz R.D. "An experimental investigation of fuel reactivity controlled PCCl combustion in a heavy-duty engine" SAE international journal of engines, 2010-01-0864, 2010.

12. Papagiannakis R.G and Hountalas D.T: "Experimental investigation concerning the effect of natural gas percentage on performance and emissions of a DI dual fuel diesel engine." Applied Thermal Engineering, Volume 23, Issue 3, February 2003, Pages 353-365.

13. Pastor J.V., Garcia-Oliver J.M., Pastor J.M., Ramirez-Hernandez J.G., "Ignition and combustion development for high speed direct injection diesel engines under low temperature cold start conditions". Fuel 90 15561566, 2011. 
14. Christian R., Knopf F., Jasmek A., Schindler W.A. New Method for the Filter Smoke Number Measurement with Improved Sensitivity. MTZ 1993; 54:16-22.

15. De Ojeda W., Zhang Y., Xie K., Han X., Wang M. and Zheng M. "Exhaust hydrocarbon speciation from a single-cylinder compression ignition engine operating with in-cylinder blending of gasoline and diesel fuels" SAE international journal of engines, 2012-01-0683, 2012.

16. Arrègle J., López J.J., García J.M., Fenollosa C., "Development of a zero-dimensional Diesel combustion model, Part 2: Analysis of the transient initial and final diffusion combustion phases", Applied Thermal Engineering 23 1319-1331, 2003.

17. Pastor J.V., López J.J., García J.M., Pastor J.M., "A 1D model for the description of mixing-controlled inert diesel sprays", Fuel 87 2871-2885, 2008.

18. Lancaster D.R., Krieger R.B. and Lienesch J.H., "Measurements and analysis of engine pressure data", SAE Paper 750026, 1975

19. Lapuerta M., Armas O. and Hernández J.J., "Diagnostic of D.I. Diesel Combustion from In-Cylinder Pressure Signal by Estimation of Mean Thermodynamic Properties of the Gas", Applied Thermal Engineering. Vol 19 № 5 pp 513-529, 1999.

20. Payri F., Molina S., Martín J. and Armas O., "Influence of measurement errors and estimated parameters on combustion diagnosis", Applied Thermal Engineering Vol 26 № 2-3 pp 226-236, 2006.

21. Way R.J.B., "Methods for Determination of Composition and Thermodynamic Properties of Combustion Products for Internal Combustion Engine Calculations", Proceedings of the Institution of Mechanical Engineers. 190(60):686-697, 1976.

22. Benajes J., Novella R., García A. and Arthozoul S., "Partially premixed combustion in a Diesel engine induced by a pilot injection at the low-pressure top dead center", Energy \& Fuels, 23, 2891-2902, 2009.

23. Splitter D., Wissink M., Kokjohn S. and Reitz R. "Effect of compression ratio and piston geometry on RCCI load limits and efficiency" SAE international journal of engines, 2012-01-0383, 2012.

\section{Glossary}

aTDC: after Top Dead Centre

$\mathrm{C}_{\mathrm{D}}$ : number of diesel fuel molecule carbons

$\mathrm{C}_{\mathrm{G}}$ : number of gasoline molecule carbons

$\mathrm{Cl}$ : Compression Ignition

CO: Carbon Monoxide

DPF: Diesel Particulate Filter

EGR: Exhaust Gas Recirculation

Eol: End of Injection

FSN: Filter Smoke Number

$\mathrm{H}_{\mathrm{D}}$ : number of diesel fuel molecule hydrogens

$\mathrm{H}_{\mathrm{G}}$ : number of gasoline molecule hydrogens

HCCl: Homogeneous Charge Compression Ignition 
ICE: Internal Combustion Engines

IVO: Intake Valve Opening

ICFB: In-Cylinder Fuel Blend

NOx: Nitrogen Oxides

ON: Octane number

PCCI: Premixed Charge Compression Ignition

PFI: Port Fuel Injector

RCCI: Reactivity Controlled Compression Ignition

RoHR: Rate of Heat Release

SoC: Start of Combustion

Sol: Start of Injection

TDC: Top Dead Centre

Tad: Adiabatic Flame Temperature

uHC: Unburned Hydrocarbon

$\mathrm{Y}_{\mathrm{N} 2}$, air: Nitrogen mass fraction of the intake air

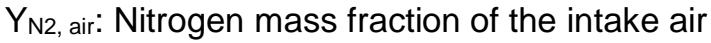

$\Phi$ : equivalence ratio

$\Phi_{\text {est: }}$ estequiometric equivalence ratio

$\Phi_{G}:$ gasoline equivalence ratio 